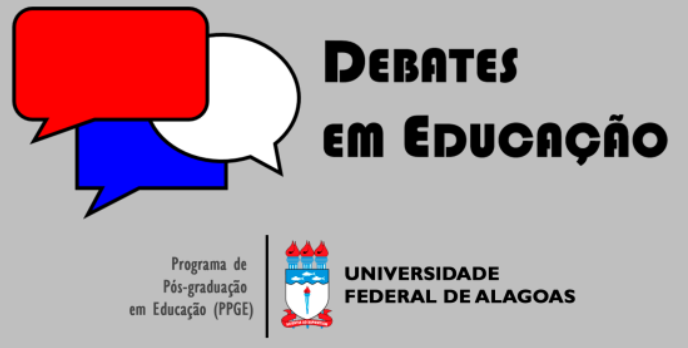

ISSN Eletrônico 2175-6600

Vol. 10 | №. 21 | Maio/Ago. | 2018

\section{A POTENCIALIDADE INTERDISCIPLINAR ENTRE ÁREAS DO CONHECIMENTO}

\section{RESUMO}

Buscando analisar a aplicabilidade do método interdisciplinar, efetuou-se uma pesquisa bibliográfica em materiais didáticos, dispostos na rede de ensino público, assim como a aplicação de questionários com alunos do ensino médio. $O$ tema central para a interpretação de dados analíticos interdisciplinares foi a disciplina de Física, lecionada entre os anos finais do ensino fundamental e ao longo do ensino médio. Os dados obtidos mostraram que há uma ampla gama de conteúdos interdisciplinares que podem ser trabalhados desde o ensino fundamental até o médio, como a estrutura do átomo, estados físicos da matéria, temperatura e operações matemáticas. Áreas das ciências naturais que trabalham moléculas, partículas, estruturas biológicas e suas interações com o meio, estão entrelaçadas dentro das ciências exatas, humanas e linguagens. Dessa forma, tópicos contextuais trabalhados durante o processo de escolarização, emergem para o potencial interdisciplinar.

Palavras-chave: Escola. Metodologia. Planejamento.

\section{INTERDISCIPLINARY POTENTIAL AMONG AREAS OF KNOWLEDGE}

Universidade Federal do Pampa (UNIPAMPA) suzianebarcellos@gmail.com

\section{Loraine Rodrigues Jardim}

(9) id

Secretaria Municipal de Educação de São

Gabriel/RS

lorodrigues2@gmail.com

\begin{abstract}
Aiming to analyze the applicability of the interdisciplinary method, bibliographic research was done on didactic materials, arranged in the public education network, as well as the application of questionnaires with high school students. The central theme for the interpretation of interdisciplinary analytical data was the discipline of Physics, taught between the final years of elementary school and throughout high school. The data obtained showed that there is a wide range of interdisciplinary contents that can be worked from elementary to high school, such as the atom structure, physical states of matter, temperature and mathematical operations. The Natural Sciences Areas that work with molecules, particles, biological structures and their interactions with the environment are intertwined within the exact sciences, humanities and languages. So, contextual topics worked during the schooling process, emerge to the interdisciplinary potential.
\end{abstract}

Keywords: School. Methodology. Planning.

Submetido em: 16/01/2018

Aceito em: 29/04/2018

DOI: $10.28998 / 2175-6600.2018 v 10 n 21 p 237-258$ 


\section{INTRODUÇÃO}

O pensar interdisciplinar parte do pressuposto de que nenhuma linha de raciocínio é completamente absoluta ou contínua. Abrir-se a outras metodologias é possibilitar formas diferentes de aprendizagem, sendo que o saber individual quando abordado em conjunto, forma preceitos sociais que moldam a sociedade (FAZENDA, 2008).

A interdisciplinaridade proporciona a integração dos conteúdos, História com Geografia, Química com Biologia, Matemática com Física, e assim, sucessivamente, sem que percebamos sua ampla distribuição contextual. Frigotto (1995, p. 26) analisou a interdisciplinaridade pela própria forma de o "homem produzir-se enquanto ser social e enquanto sujeito e objeto do conhecimento". Aprofunda-se no caráter dialético onde o significado é a compreensão, orientação e ação, ligadas a elementos da realidade do indivíduo. Pode acontecer naturalmente se houver sensibilidade para o contexto, mas sua prática demanda trabalho didático de um ou mais professores. (GOULART et al., 2011).

A disciplina de Física tem por definição: ciência que investiga as propriedades da matéria, estruturas dos sistemas, e suas leis fundamentais (FERREIRA, 2000). Apesar de os conteúdos da disciplina de Física serem cotidianos, muitas pessoas não compreendem como esse componente curricular influencia a vida no planeta Terra. A interação entre moléculas de água, quando dispostas a temperaturas extremas como o calor acima de $100^{\circ} \mathrm{C}$, proporciona o processo físico de ebulição, produzindo energia e mudança na matéria. Esse fenômeno está presente em nosso dia a dia, pois aquecemos água para o preparo de um café, chá ou alimentos. Outro fenômeno físico presente em nosso cotidiano é o degelo das calotas polares, intensificado pelo efeito estufa, um fenômeno natural responsável pela manutenção do calor na superfície terrestre, é tema de fóruns e projetos de ações globais, envolvendo a Organização das Nações Unidas (ONU). Evidentemente, o processo de degelo é um fenômeno físico muito comum, estudado desde anos inicias do ensino fundamental. Relacionado à mudança de estado físico da matéria (sólido para líquido), promove o derretimento das calotas polares, aumento do nível do mar e bruscas mudanças em correntes marinhas, influenciando direta e indiretamente o clima global (SILVA; LIMA, 2009).

Com avanços científicos e melhorias nas técnicas de produção industrial, a Física passou a ser reconhecida como essencial para a evolução e para o progresso da humanidade. Dessa forma, passou a ser ministrada como disciplina obrigatória nas escolas para anos finais do ensino fundamental, e para todos os anos do ensino médio, desde o vigor da LEI no 9.394 de 20 de dezembro de 1996 (BRASIL, 1996). Contudo, a linguagem 
da Física ainda não é completamente compreendida, e seus fenômenos e processos, pouco utilizados como "ferramenta" metodológica para intervenções interdisciplinares entre as ciências da natureza (SPEYER, 1995).

Neste contexto, efetuou-se uma busca em materiais didáticos, interligando conteúdos de potencial interdisciplinar. Escolheu-se como conteúdo central a Termologia, lecionada a partir do $2^{\circ}$ ano do ensino médio, componente obrigatório da disciplina de Física. Segundo Bonjorno (2013, p. 267), a termologia é a "ciência que estuda fenômenos relacionados ao aquecimento e resfriamento dos corpos, sua interação termodinâmica com a matéria". Os tópicos abordados dentro desse contexto são: Leis da Termodinâmica; Medidas de Temperatura e Estados Físicos da Matéria.

A partir do tema estipulado, iniciou-se a pesquisa literária na busca de pontos convergentes, utilizando livros, apostilas, planos de aula, revistas, artigos científicos e cadernos pessoais de professores da escola. A visão procedimental foi interligar e acoplar disciplinas, entrelaçadas por tópicos repetitivos, sendo que, o material alvo desse trabalho foi disponibilizado na biblioteca da escola. Nesse local estão dispostos livros e materiais didáticos utilizados pelos discentes, que recorrem a estes no decorrer de sua formação escolar, sendo muitas vezes o único aos quais têm acesso.

O presente trabalho buscou de forma interdisciplinar analisar por meio de uma pesquisa qualitativa e quantitativa, conteúdos sistematizados do ensino fundamental e médio da escola Estadual de Ensino Médio João Pedro Nunes, município de São Gabriel, Rio Grande do Sul, no período de 2015 a 2017. Objetiva-se promover uma orientação geral aos autores de futuros artigos sobre ações multidisciplinares, envolvendo a disciplina de Física, para a organização e, principalmente, redação de artigos científicos.

\section{REVISÃO BIBLIOGRÁFICA}

Englobando os conceitos pedagógicos e epistemológicos na estruturação de áreas do conhecimento, destaca-se a metodologia interdisciplinar. Um planejamento interdisciplinar na área pedagógica ocorre quando, duas ou mais disciplinas relacionam conteúdos (FAZENDA, 2011). Com tal inter-relação, elabora-se um aprofundamento do conhecimento, proporcionando uma dinâmica ao mecanismo do ensino. Dessa forma, é possível enriquecer o conhecimento agregando conteúdos diversificados, possibilitando aos discentes uma melhor compreensão, interpretação e elaboração de um único contexto (SANTOMÉ, 1998). 
$\mathrm{Na}$ área da epistemologia, um dos tópicos estudados é o conhecimento em seu aspecto de produção, reconstrução e socialização, onde a ciência exerce seus preceitos estruturais, metodológicos e auxilia o sujeito na formulação de conceitos relacionados à realidade (MORAES, 2012).

A interdisciplinaridade pode integrar-se em outras áreas específicas, com o propósito de promover uma articulação entre o aluno, professor e cotidiano (FAZENDA, 2001). Encontramos forte paralelismo entre os conteúdos lecionados, como por exemplo: os temas transversais. Sob esse aspecto, o processo educacional não está apenas limitado à escola, pois temos a interdisciplinaridade como domínio social e cultural.

O resultante do convívio interdisciplinar é um movimento que caminha para novas formas de educação e conhecimento, difusão e transferência, sistema e produção que modificam todo o resultante do processo de aprendizagem (CURY, 2000). Cabe ao educador manusear, modular e aplicar este método, visando à melhoria no aprendizado de seus discentes em áreas do conhecimento que, relatam maiores índices de evasão ou de dificuldades de contextualização. Segundo Fazenda (2008, p. 18),

Se definirmos interdisciplinaridade como atitude de ousadia e busca frente ao conhecimento, cabe pensar aspectos que envolvem a cultura do lugar onde se formam professores. Assim, na medida em que ampliamos a análise do campo conceitual da interdisciplinaridade, surge à possibilidade de explicitação de seu espectro epistemológico e praxeológico.

Teorias abordam a interdisciplinaridade como um movimento influenciável, a partir do momento em que seja possível elaborar um pensamento complexo, em direção á contextualização (DARBELLAY, 2011). Articulações bilaterais do conhecimento são produzidas historicamente pela humanidade, atuam no processo de ensino e aprendizagem com o intuito de promover a reforma interdisciplinar (ALMEIDA; CARVALHO, 2007).

As instituições de ensino são ambientes propícios à execução de condutas sociais, para a formação de cidadãos. Nesse espaço, pode-se modular a vida coletiva, aplicando práticas que visem a uma reflexão do aluno para o meio social em que ele se encontra (CORTELLA, 2014). É nela que a possibilidade de mudar o senso comum é real, cabendo ao professor elaborar objetivos e procedimentos que agucem as relações interdisciplinares (FAZENDA, 2011).

Análises entre as séries iniciais do ensino fundamental nos mostram como a interdisciplinaridade é efetivada, pois o pedagogo trabalha disciplinas em conjunto, sem que haja uma fragmentação. Podemos elaborar inúmeras formas de exercer a interdisciplinaridade, pois todos os conteúdos se conectam em algum ponto convergente (CARVALHO et al., 2010). Devido à complexidade atual da sociedade, constantemente em 
plena mutação, é animador promover mudanças na área da educação. A interdisciplinaridade refere-se a movimentos sociais e culturais, atuando em objetivos reais, elaborado pelas ciências do conhecimento (JAPIASSU, 1976).

\section{METODOLOGIA}

Após uma leitura prévia de 486 livros, 24 artigos, 12 revistas e 148 planos de aula disponibilizados pelos professores e direção da escola, efetuou-se a organização dos tópicos de componentes curriculares lecionados em sala de aula. $\mathrm{Na}$ escola tradicional, o conhecimento é moldado como uma epistemologia, onde, segundo Saviani (1986, p. 06), "a escola se organiza, pois, como uma agência centrada no professor, o qual transmite, segundo uma gradação lógica, o acervo cultural aos alunos". Nessa perspectiva, ainda encontramos metodologias tradicionais de ensino, baseadas na Teoria da Escola Tradicional, que até certo ponto, pode ser modulada e acoplada em novas formas de escolarização.

Cada componente curricular foi analisado e computado em planilhas, e subdividido em temas interligados interdisciplinarmente e transversalmente. A prática pedagógica desta pesquisa utilizou recursos digitais como computadores e aparelho celular, adaptando-se a novas tecnologias que auxiliam em formulações diferenciadas de ensino, para obtenção de resultados qualitativos relevantes (LUCKESI, 1999).

A escolha interdisciplinar do conteúdo de Física foi promovida segundo os seguintes preceitos: 1) tópico repetitivo em mais de uma disciplina; 2) material didático (gráficos, figuras e tabelas) igualitário; 3) relação contextual interligada; 5) objetivo central condizente. Por intermédio destes filtros de seleção reconectou-se o maior número de disciplinas, distribuídas de forma fragmentada entre áreas diversificadas do conhecimento.

As planilhas foram organizadas da forma mais harmônica possível, utilizando a bibliografia com temas semelhantes (Quadro 1 e 2). Após análises dos resultados obtidos no período de seis meses de pesquisa, elaboraram-se tabelas representativas com os principais temas de potencial interdisciplinar. 
Quadro 1 - Triagem de alguns conteúdos com potencial interdisciplinar

\begin{tabular}{|c|c|c|}
\hline Área do Conhecimento & Disciplina & Conteúdo Central \\
\hline \multirow{5}{*}{$\begin{array}{c}\text { Ciências } \\
\text { Da } \\
\text { Natureza } \\
\text { Ciências Exatas }\end{array}$} & $\begin{array}{c}\text { Ciências } \\
\text { Naturais (EF) }\end{array}$ & $\begin{array}{c}\text { Estrutura da Terra } \\
\text { Propriedades da Matéria } \\
\text { Estruturas das Moléculas } \\
\text { Estrutura do Átomo }\end{array}$ \\
\hline & Química (EM) & $\begin{array}{c}\text { Moléculas } \\
\text { Matéria e Energia } \\
\text { Unidades de Medida } \\
\text { Substâncias Químicas } \\
\text { Estrutura do Átomo } \\
\text { Ligações Químicas } \\
\text { Reações Químicas }\end{array}$ \\
\hline & Física (EM) & $\begin{array}{c}\text { Interação entre Moléculas } \\
\text { Movimento e Força } \\
\text { Trabalho e Energia } \\
\text { Estrutura do Átomo } \\
\text { Eletromagnetismo } \\
\text { Sistema Internacional de Medida } \\
\text { Eletricidade }\end{array}$ \\
\hline & Biologia (EM) & $\begin{array}{l}\text { Componentes da Célula } \\
\text { Estruturas Biológicas } \\
\text { Interação entre Moléculas } \\
\text { Estrutura do Átomo } \\
\text { Estados Físicos da Matéria }\end{array}$ \\
\hline & Matemática (EM) & $\begin{array}{c}\text { Operações Básicas } \\
\text { Resolução de Problemas } \\
\text { Unidade de Medida } \\
\text { Geometria } \\
\text { Potencialização } \\
\text { Radiação }\end{array}$ \\
\hline \multirow{5}{*}{$\begin{array}{l}\text { Ciências } \\
\text { Humanas }\end{array}$} & Geografia (EM) & $\begin{array}{c}\text { Atmosfera Terrestre } \\
\text { Temperatura e Clima } \\
\text { Estados Físicos da Matéria }\end{array}$ \\
\hline & \multirow{2}{*}{ História (EM) } & Revolução Industrial \\
\hline & & Capitalismo e Socialismo \\
\hline & Sociologia (EM) & Capitalismo e Socialismo \\
\hline & Filosofia (EM) & Realismo e Naturalismo \\
\hline \multirow{3}{*}{ Linguagens } & Artes (EM) & A Industrialização \\
\hline & Português (EM) & Realismo e Naturalismo \\
\hline & Literatura (EM) & Realismo e Naturalismo \\
\hline
\end{tabular}

E.F - Ensino Fundamental.

E.M - Ensino Médio.

Fonte: Autor (2017). 
Quadro 2 - Triagem de alguns conteúdos com materiais didáticos de potencial interdisciplinar.

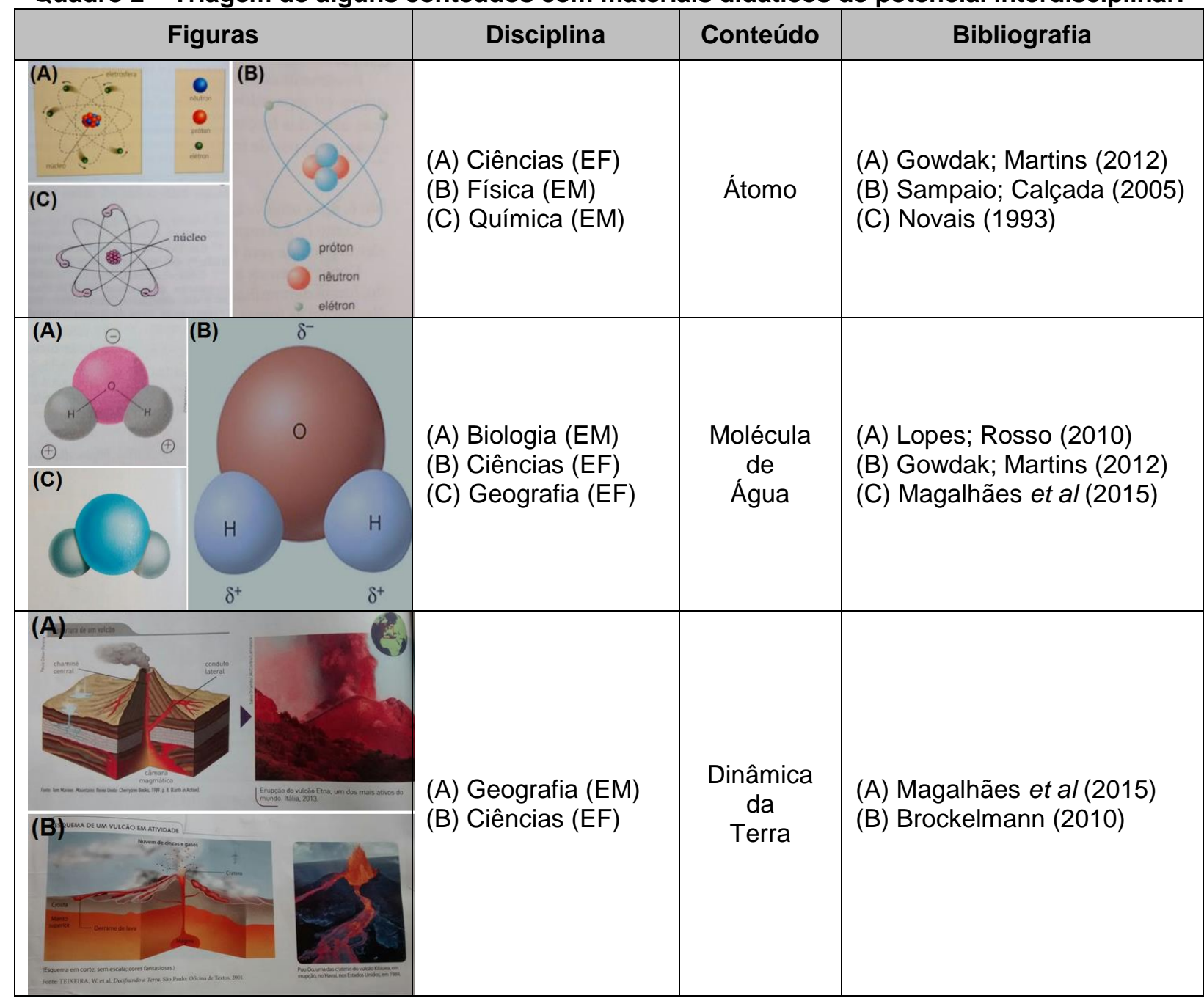

E.F - Ensino Fundamental.

E.M - Ensino Médio.

Fonte: Autor (2017).

Interligar conteúdos reflete na explicação contextual do mesmo, pois é através das dificuldades que os erros inconsistentes revelam-se aparentes, sendo cabíveis mudanças para tentativas propostas no trabalho interdisciplinar (MACHADO, 2000).

A partir destes tópicos estabelecidos, formularam-se questionários com perguntas objetivas, descritivas e de raciocínio lógico, buscando compreender e encontrar as principais falhas de assimilação e contextualização destes conteúdos entre os alunos (Quadro 3). 


\section{Quadro 3 - Modelo de questionário aplicado com alunos do $3^{\circ}$ ano do ensino médio.}

\section{Questionário $3^{\circ}$ ano do Ensino Médio}

1) Marque um $X$ na(s) alternativa(s) correta(s). Em quais disciplinas você estudou o conteúdo átomo e estados físicos da matéria?
(a) Física
(b) Química
(c) Biologia

2) As estruturas básicas das moléculas são estudadas desde os anos finais do ensino fundamental, e por todo o ensino médio. Desta forma, você poderia mencionar em quais disciplinas você já estudou este conteúdo?

3) Dentre as propriedades físicas da matéria, três estados são comumente visualizados: sólido, líquido e gasoso. Dê exemplos desses estados da matéria, e descreva onde são encontrados no dia a dia. Relacioneos com pelo menos uma disciplina, na qual tenham sido trabalhados.

4) A água é um solvente universal, importante para inúmeras funções orgânicas e inorgânicas. Descreva com suas palavras uma função da água, trabalhada dentro das respectivas disciplinas:
(a) Física:
(b) Química:
(c) Biologia:

5) Marque um X na(s) alternativa(s) correta(s). Em que disciplina(s) você utiliza cálculos básicos como operações?
(a) Matemática
(b) Física
(c) Química
(d) Biologia
(e) Outras

6) Relacione as colunas. Obs: pode haver mais de uma alternativa correta.
(a) Átomo
(b) Estados Físicos da Matéria
(c) Temperatura
(d) Clima
(e) Revolução Industrial
(f) Industrialização
(g) Naturalismo e Romantismo
)Física
) Química
) Geografia
) História
) Sociologia
) Filosofia
) Literatura

7) Marque um $X$ na alternativa correta. $O$ tema revolução industrial abrange conteúdos da disciplina de física?

( ) Sim

( ) Não

8) Marque um $X$ na(s) alternativa(s) correta(s). O advento da máquina a vapor impulsionou a economia global. Grandes personalidades da história como Rudolf Clausius (1850), deixaram explícito que o calor gera energia e proporciona o trabalho. Assim, foi possível o desenvolvimento de motores com propulsão a calor. Para tal feito, o físico utilizou:
(a) cálculos matemáticos
(b) explicações físicas como mudança de estado matéria
(c) longos textos que dispunham de explicações gramaticais
(d) a estrutura de moléculas e como seus elementos poderiam transmitir energia

Fonte: Autor (2017).

Os questionários foram redigidos de acordo com os níveis de escolarização, aplicados aos discentes do ensino médio da mesma escola onde ocorreu a pesquisa, e, respectivamente, usuários dos mesmos materiais didáticos analisados. Os resultados obtidos nos questionários foram computados e dispostos em gráficos, figuras e tabelas estatísticas, construídos após a aplicação do teste ANOVA com 5\% de significância e pelo programa Excel 2010. 


\section{RESULTADOS E DISCUSSÃO}

\subsection{Ciências da natureza}

Para melhor discutir a interdisciplinaridade, por meio de todos os dados obtidos, escolheu-se a palavra ELOS para interligar as áreas do conhecimento. Realizou-se na área das ciências da natureza uma análise profunda no material didático de Física, Biologia e Química que apontou como resultantes conteúdos com promissor potencial interdisciplinar.

Os tópicos encontrados em livros de diferentes disciplinas de uma mesma área possuem categorias similares, fotos reais, figuras ilustrativas e textos de contextualização que não apresentaram diferenças notórias entre os temas abordados.

O conteúdo Átomo e Estados Físicos da Matéria, apresentou nas disciplinas pesquisadas forte tendência transversal, uma vez que coexistem em um mesmo período escolar, porém, encontramos falhas de assimilação e contextualização pelos alunos (Figura 1). Os mesmos conceitos utilizados por Bruni (2013) em Química para definir os estados físicos da matéria: sólido, líquido e gasoso são praticamente igualitários aos de Bonjorno (2013) em Física, assim como os de Biologia em Santiago (2013). Esses pontos convergentes devem ser tencionados, para a elaboração de um ELO interdisciplinar em áreas transversais do conhecimento.

Figura 1 - Dados coletados por meio de questionários realizados com alunos do ensino médio. Pergunta: em quais disciplinas você estuda o conteúdo átomo e estados físicos da matéria?

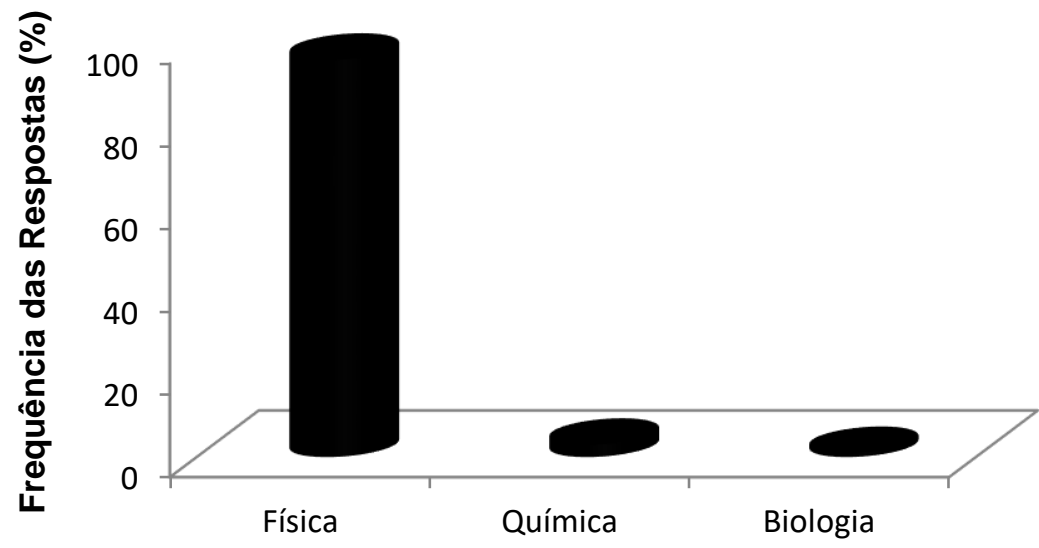

Disciplinas

Fonte: Autor (2017).

A pesquisa aponta nesse tópico abordado a possibilidade de eliminação de obstáculos entre as disciplinas de Física, Química e Biologia, referente a esses conteúdos. 
A interpretação de ambas as bibliografias nos revela como é presente a educação reprodutora, havendo uma homogeneidade dos conteúdos abordados (LUCKESI, 1999). Nesse caso, o tema central "estrutura atômica" é muito similar entre as disciplinas de Ciências (ensino fundamental), e a grande área das Ciências da Natureza (ensino médio). Não podemos rotular este aspecto como "negativo", mas como uma ponte indutora para ligações interdisciplinares. Quando falamos de educação reprodutora é viável lembrar que, a reprodução também é uma metodologia viável de ensino, que pode auxiliar o sujeito no aprimoramento de um elemento para seus condicionantes (SAVIANI, 1986).

\subsection{Ciências exatas}

Podemos compreender melhor como a interdisciplinaridade funciona, quando adentramos em disciplinas que abrangem temáticas diversificadas, como as ciências exatas. Um recurso dinâmico e infalível é a disciplina de Matemática; ela promove ELOS entre todos os conteúdos imagináveis, facilitando o processo de contextualização em diversas áreas do conhecimento (LIMA, 2012). As ações interdisciplinares teóricas e práticas aplicam-se continuamente, formulando novas possibilidades horizontais e verticais para o conhecimento. "A interdisciplinaridade não fica apenas no campo da intenção, mas é exercida pela ação" (FAZENDA, 1993, p. 35).

O exercício interdisciplinar integra esse conteúdo escolar, resultando em grande avanço metodológico. Desde o $4^{\circ}$ ano do ensino fundamental, trabalham-se operações primordiais que, efetuam a construção de fórmulas necessárias para a elaboração de cálculos, relacionados e utilizados pela Física, Química, Biologia.

A interdisciplinaridade não tem por objetivo eliminar disciplinas; trata-se de torná-las mais comunicativas entre si, unir os processos históricos e culturais, na busca da concepção plena do conhecimento, desviando-se da obstrução fragmentária (FAZENDA, 2011). Desde os anos oitenta, a Finlândia estrutura um novo modelo de ensino, chamado de "Fenômeno da Interdisciplinaridade". Nele os conteúdos do currículo não são abordados por disciplinas, mas de maneira interdisciplinar. O aprendizado não é fragmentado; é unificado de uma forma geral, na qual o próprio aluno reconhece um determinado assunto, relacionando-o a determinada área do conhecimento. Nesse sistema, o professor passou a ser um mediador do conhecimento, oferecendo suporte e estrutura para proporcionar 0 aprendizado dos alunos (BASTOS, 2017).

Os números expressam grandes informações, muitas vezes não compreendidas, quando dispostas apenas em palavras. O cálculo é direcionado para auxiliar em todas as 
áreas do conhecimento. Com o advento do Teorema Fundamental do Cálculo, estabeleceuse uma ampla conexão entre as ciências extas, ciências da natureza, ciências humanas e linguagens. O cálculo é componente integrador do processo de ensino e aprendizagem, sendo desenvolvido a partir da Álgebra e Geometria (GOMES, 2012).

A dedicação ao estudo, relacionado às diferenças numéricas, trazem não apenas valores como resultados finais; elaboram respostas que até mesmo as palavras não seriam capazes de explicar (MENDELSON, 2007). Porém no processo de escolarização, percebeu-se por meio do material didático analisado, assim como, em respostas dos alunos aos questionários, uma falha preocupante para um grande grupo de alunos integrantes do ensino médio, para os quais não foi possível a assimilação de cálculos (operações) a outras áreas do conhecimento (Figura 2). Figura 2 - Dados coletados por meio de questionários realizados
com alunos do $1^{\circ}$ ao $3^{\circ}$ ano do ensino médio. Pergunta: em quais
disciplinas você utiliza cálculos básicos como operações?

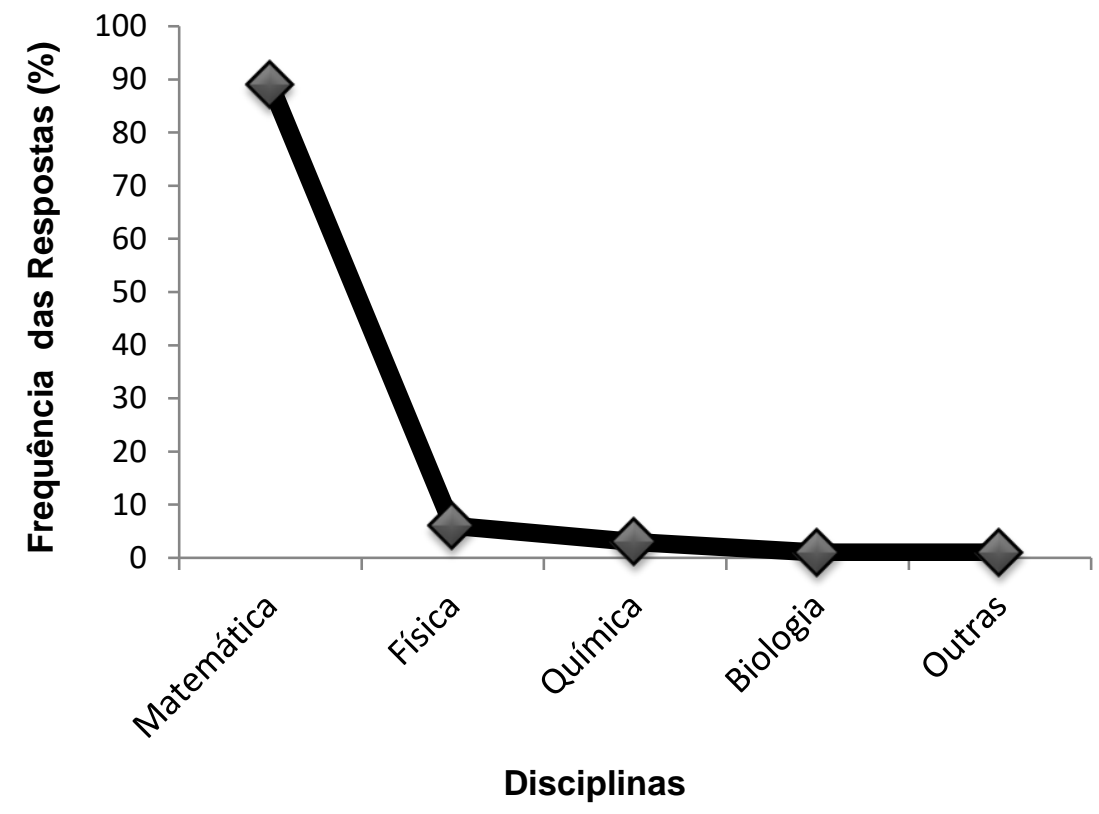

Fonte: Autor (2017).

Observando uma proposta de exercício matemático disposto no livro do $4^{\circ}$ ano do ensino fundamental, foi possível realizar uma adaptação para contrapor uma contextualização alternativa real, cabível em outras disciplinas. Dessa forma elaboramos um ELO entre temas transversais de ciências da natureza, humanas e exatas.

Exemplo fictício disposto no material didático analisado: A comida que restou para 3 náufragos seria suficiente para alimentá-los por 12 dias. Um deles resolveu saltar e tentar chegar à terra firme nadando. Com um náufrago a menos, qual será a duração dos alimentos? (DANTE, 2014, p. 09). 
Exemplo idealizado com potencial interdisciplinar: Em crise econômica atual os suplementos alimentares de uma família são suficientes para sustentá-los por 12 dias. Um dos integrantes da família viajou a procura de trabalho, por quantos dias os mesmos alimentos irão durar? (AUTOR, 2017).

Existe uma imensa lacuna entre disciplinas de uma mesma base curricular, quando analisados contextos educacionais. Se ao invés de trabalhar exemplificações fictícias, os discentes trabalhassem contextos dinâmicos, relacionados às disciplinas específicas que ainda não dispõem. Alunos que cursam os anos finais do ensino fundamental I trabalham em cálculos muitos exercícios de raciocínio lógico, como: soluções de problemas. Nesses casos, poderíamos empregar questões básicas de Química, Física e Biologia, que instigassem o aluno a trabalhar um tema futuro.

Um exemplo real desta colocação são os exercícios fictícios de raciocínio lógico para cálculos. Dante (2015) possui em seu material didático (disciplina de Matemática para o $7^{\circ}$ ano do ensino fundamental), amplos ELOS interdisciplinares para exemplificações em exercícios de raciocínio lógico, porém, nesse material didático encontram-se palavras vazias, que, se melhores trabalhadas, poderiam ser utilizadas em prol da interdisciplinaridade. O cotidiano social é um contexto infinito, que desde as séries inicias até as finais do ensino fundamental, proporciona ao aluno seu legado de aprendizagem e apropriação do conhecimento, desfragmentando conteúdos (BRASIL, 2002).

Dessa forma, é possível compreender o dilema do jogo de palavras vazias, que por não serem verdadeiras, não conduzem à ação e assimilação contextual (FREIRE, 1987). A ausência da contextualização reflete a necessidade de que, o conhecimento não deve ser disposto de forma dicotômica. Essa realidade transparece na formação educacional e social de cada indivíduo, pois o vazio interdisciplinar existente e reflete a importância de rever o sistema de escolarização atual.

Os Parâmetros Curriculares Nacionais expressam que, o montante do aprendizado provindo do ensino fundamental, é utilizado como ferramenta de contextualização para o ensino médio (BRASIL, 2002). As disciplinas estão subdivididas em áreas do conhecimento por possuírem uma ligação. Assim, de uma forma geral, o aprendizado gradativo é ao final contemplador.

Somente a inovação e técnicas ousadas, poderão elaborar ELOS interdisciplinares entre estes conteúdos do ensino fundamental e médio. A construção do conhecimento, relacionado ao conteúdo escolar, é altamente influenciado pelo ambiente social. A interpretação individual deve lançar problemas da atualidade e tradicionais, na busca da exploração de ideias que reflitam a realidade (GUIMARÃES, 2004). O processo de 
mudanças deve ocorrer de forma crítica e reflexiva, buscando mudar paradigmas ligados a metodologias educativas.

No ensino médio e fundamental, percebe-se um paralelismo em fórmulas matemáticas para efetuação de cálculos, porém, os períodos trabalhados não são similares. No material analisado encontramos as operações matemáticas básicas (adição, subtração, multiplicação e divisão), utilizadas para cálculos de conversão de temperatura (BONJORNO, 2013); distribuição geográfica das estações e clima em grau Celsius (VEDOVATE, 2010); ponto de fundição e fusão de metais pesados e derivados de processos de industrialização (COTRIM, 2012). Em ciências da natureza, os mesmos cálculos também são aplicados em Biologia para contextos diversificados, como por exemplo: hereditariedade e cruzamentos gênicos (SANTIAGO, 2013); em Química as operações são fundamentais em reações químicas, misturas e substâncias, camada de valência e carga atómica (BRUNI, 2013), assim como, igualitariamente em Física na termodinâmica. Percebe-se que as operações matemáticas são ferramentas primordiais para todos os conteúdos do período de escolarização, assim, é cabível a este, um grande potencial interdisciplinar com a disciplina de Física (Figura 3).

Figura 3 - Esquema representativo entre áreas do conhecimento e suas relações interdisciplinares durante os períodos da escolarização.
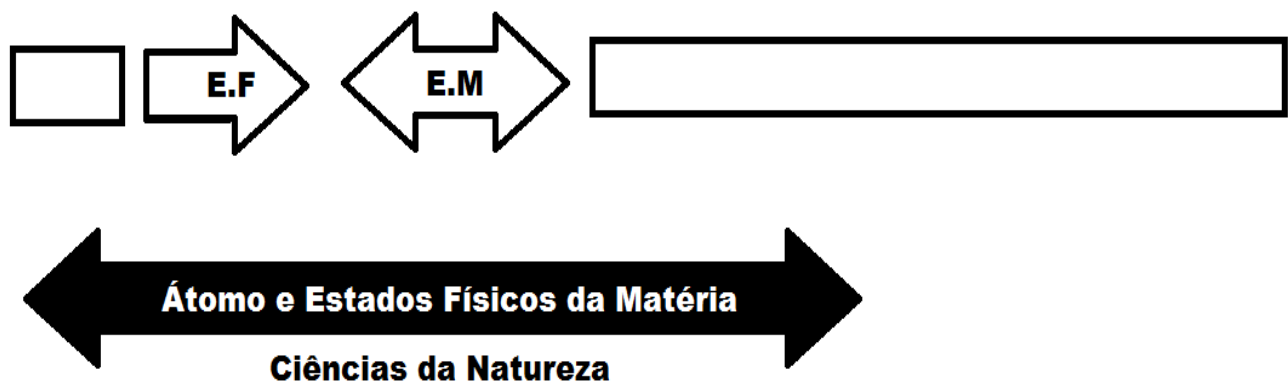

Ciências da Natureza

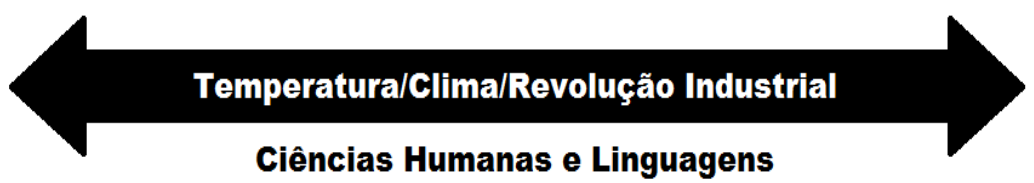

Ciências Humanas e Linguagens

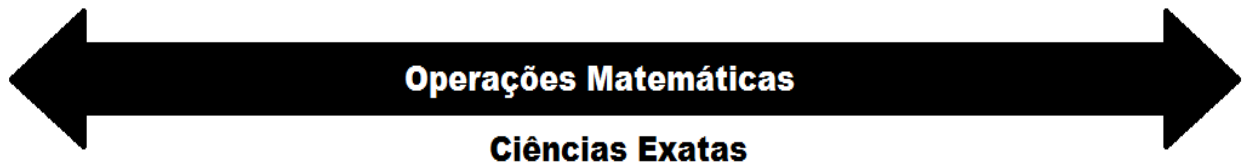

E.F - Ensino Fundamental (séries finais).

E.M - Ensino Médio.

Fonte: Autor (2017). 


\subsection{Ciências humanas e linguagens}

Quando analisado o material didático disposto pela grade da área das ciências humanas e linguagens, observa-se como resultante a similaridade entre os conteúdos lecionados, referentes à temperatura e clima. Relevante é a observação da ocorrência de recursos didáticos explicativos similares ou até mesmo iguais, tais como: ilustrações (figuras e gráficos), fotos realísticas e trechos de contextualização.

O conteúdo trabalhado no ensino médio na disciplina de Geografia aborda o conjunto de condições atmosféricas que, caracteriza uma região pela influência de temperaturas e suas ações termodinâmicas no planeta terra (VEDOVATE, 2010). Trabalha-se a especificidade climática de acordo com o posicionamento global e influência meteorológica, que caracteriza o estado climático da atmosfera em determinadas áreas geográficas (MAGNÓLI, 2010). É perceptível que o tema termologia, presente na Física, é lecionado paralelamente no período do $2^{\circ}$ ano do ensino médio, sendo capaz de promover um ELO interdisciplinar com os conteúdos dispostos nas disciplinas de Geografia e Física.

Uma integração entre esses conteúdos promove complemento em ambas as disciplinas, cabível de trabalho paralelo, elaborando um elemento único para enriquecer o conhecimento. O tema "clima", em Geografia, é disposto em grau Celsius; igualmente em Física se trabalham as mesmas medidas para se compreender as ações da temperatura na matéria. Nessa convergência contextual é possível proporcionar uma transcendência, uma vez que, a interdisciplinaridade propõe uma revisão e intensificação ao diálogo. As trocas da integração contextual entre diferentes campos do saber efetivam-se em prol da unificação do conhecimento (JAPIASSU, 1976).

Reforçando essa direção, ressalta-se uma tendência à especialização exponencial, que nada mais é do que a fragmentação para amplitude de determinada área do conhecimento. Quando se contextualiza individualmente algum tema, como por exemplo: cálculos, de alguma forma cria-se uma barreira fictícia a outras disciplinas. O refinamento entre conteúdos parte do ponto em que "Cada totalidade, coincide ao todo com pequenas partes, por intermédio de uma análise cada vez mais fina" (POMBO, 1993, p. 5). A especialização é cotidianamente considerada como ferramenta de ensino, pois não se pode saber tudo, porém, pode-se refinar algo para obter um melhor domínio de determinada área ou função (FAZENDA, 2011).

Temos uma clara visão da falta de interligação entre disciplinas, afastando áreas do conhecimento, uma vez que, não ocorre a assimilação contextual do que é aprendido (LUCK, 2001). Para proporcionar um aprendizado interdisciplinar, é necessário abrir o 
senso destemido do conhecimento, efetivar experiências inovadoras e reais, para que futuramente possamos discutir novas possibilidades metodológicas (SANTOMÉ, 1998).

A Revolução Industrial, considerada como um dos alicerces de nossa sociedade atual impulsionou conceitos que são regentes sociais e culturais. (TOMAZZI, 2013). Esse tema aborda o pensamento formulador dos alicerces da sociedade, sendo um forte ponto de potencial interdisciplinar. O conteúdo coloca em xeque a ampla dimensão do conhecimento interdisciplinar, como pode ser trabalhado em mais de uma disciplina durante todo o ensino médio.

Partindo deste pressuposto, a interdisciplinaridade se caracteriza pela intensa troca contextualizada dos conteúdos abrangentes da Revolução Industrial, continuamente imperceptíveis, tanto pelo corpo docente, quanto pelo discente.

A inexistência do diálogo, trocas experimentais e relacionamentos interpessoais, colocam aqui o quanto se repete o mesmo conteúdo disciplinar, desde anos finais do ensino fundamental ao médio. A recuperação do ELO perdido nesse conteúdo busca encontrar o sentido epistemológico do papel do saber, primordial para o encontro do indivíduo com o conhecimento anterior e posterior à prática (GOMES, 2012).

A máquina a vapor modificou a humanidade, moveu a sociedade rumo ao conceito capitalista (BITTENCOURT, 2008). Graças aos físicos e engenheiros elaboradores das leis termodinâmicas, o mundo descobriu como o calor pode ser convertido em energia para proporcionar trabalho (COTRIM, 2012). Historicamente, essa descoberta revolucionou os meios de produção - do artesanal (lento e delicado), necessitando de grande mão de obra qualificada, para a máquina (rápida e contínua), que propulsionou a economia continental (COTRIM, 2002). Dessa forma, a interdisciplinaridade pode ser exercida entre disciplinas variadas, que trabalham o mesmo contexto, visando garantir a construção de um conhecimento globalizante. A visão integradora pode proporcionar a queda de obstáculos, auxiliando a construção do conhecimento (GADOTTI, 1993).

Um tema como esse, portador de uma ampla gama interdisciplinar, infelizmente não é contextualizado continuamente pelo corpo docente. A Revolução industrial é trabalhada entre os anos finais do ensino fundamental, e por todo o ensino médio, contendo conteúdos importantes para a compreensão do aluno em relação à absorção do conhecimento. Nas disciplinas de Português e Literatura, está presente em textos que expressam o peso dessa era na sociedade (AMARAL et al., 2013); assim como na Física, onde se trabalham as leis da termodinâmica, contendo exemplificações com a máquina a vapor (BONJORNO, 2013). Esse contexto é altamente utilizado pela Física, possuindo uma alta ligação com a era da industrialização. Exemplos de deslocamento por ações termodinâmicas convergem com o 
advento do período de industrialização, porém, em dados obtidos nos questionários aplicados aos alunos do ensino médio, percebe-se que poucos efetuam essa assimilação contextual (Figura 4).

De acordo com as novas formulações de planejamento para o ensino, visa-se distinguir áreas como ciências da natureza e humanas, intituladas opcionais para o aluno; já as ciências exatas e linguagens serão obrigatórias (BRASIL, 2016). De alguma forma o corpo discente que participar dessa nova modalidade de ensino terá disciplinas ausentes em sua formação educacional, propiciando um déficit de tópicos importantes no processo de ensino e aprendizagem, sendo de suma importância nessa fase o trabalho interdisciplinar.

\section{Figura 4 - Dados coletados por meio de questionários realizados com alunos do $1^{\circ}$ ao $3^{\circ}$ ano do ensino médio. Pergunta: 0 tema revolução industrial abrange conteúdos da disciplina de física?}

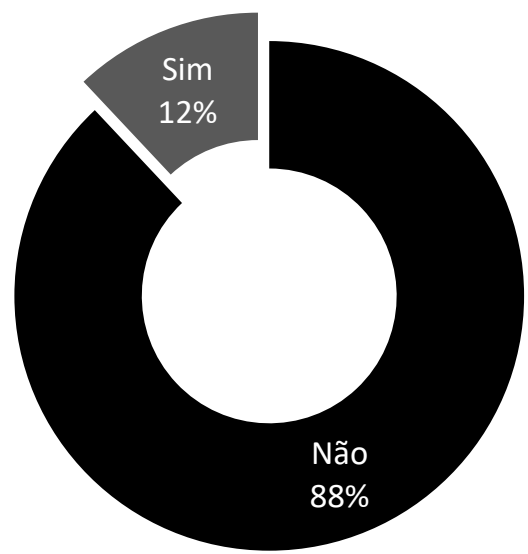

Fonte: Autor (2017)

Em contrapartida, nota-se o estabelecimento do processo do saber por acumulação, que pode influenciar o resultado disposto acima. Esse método é relativamente fragmentado, similar ao empilhamento de pedras, onde tamanhos diferentes e pesos diferentes, quando em acúmulo, desabam (FAZENDA, 1993). Discentes trabalham paralelamente o mesmo conteúdo, sem o desenvolvimento da percepção. Nesse aspecto, é importante ressaltar que as disciplinas são lecionadas determinadamente em suas áreas, e que muitas vezes podem levar à inferência de que não possuem relações (ALMEIDA; CARVALHO, 2007). Esse método induz à crença de que os assuntos não são concomitantes, não possuem relação e sequenciamento, dificultando a assimilação da linguagem expressada (AMARAL et al., 2013).

O professor é o mediador do conhecimento, deve instigar e questionar o saber. Esse envolvimento torna-se emocional e incluso de divisões, mas não é como realmente ocorre 
em sala de aula. Vemos este reflexo na repetição de conteúdos, e no desprezo de seu uso interdisciplinar. Baseado no método tradicional repetitivo de aprendizado, o ensino fragmenta de forma linear as áreas do conhecimento, e mesmo que o aluno passe e repasse o mesmo conteúdo em História, Português, Sociologia, Filosofia e Artes, não desenvolve a interligação contextual. A interdisciplinaridade visa à interligação entre disciplinas (COIMBRA, 2000), dessa forma, a repetição de um determinado conteúdo pode ser trabalhado de forma interdisciplinar, propondo um remanejo no tempo e material didático disposto (Tabela 1).

Essas problemáticas refletem na sociedade, cada vez mais tecnológica, que formula pesquisas basais e sem aprofundamento contextual, onde algumas pesquisas se voltam apenas para o objetivo almejado, e não para os caminhos pelos quais se chegarão ao objetivo. Até o $4^{\circ}$ ano do ensino fundamental, os alunos possuem quase que plenamente 0 mesmo professor; ao progredir para os anos finais, o conjunto de novos professores, que por sua vez lecionam diferentes disciplinas de forma sublinear, evidencia uma desarticulação do conteúdo. De forma geral, falta de interligações entre áreas do conhecimento proporcionam ao sujeito a falta de compreensão, pois o ensino é um conjunto articulador do sujeito em meio à sociedade (FREIRE, 1987).

Tabela 1 - Representação dos principais tópicos encontrados na bibliografia de potencial interdisciplinar relacionados com áreas de ciências da natureza, exatas, humanas e linguagens.

\begin{tabular}{cccc}
\hline Período & Disciplina & Conteúdo Central & N \\
\hline $1^{\circ}$ e $2^{\circ}$ ano E.M & Biologia/Química/Física & Átomo & $123_{\mathrm{c}}$ \\
\hline $1^{\circ}$ e $2^{\circ}$ ano E.M & Biologia/Química/Física & Estados físicos da Matéria & $71_{\mathrm{d}}$ \\
\hline $1^{\circ}$ ao $3^{\circ}$ ano E.M & Matemática & Operações & $108_{\mathrm{e}}$ \\
\hline $2^{\circ}$ ano E.M & Geografia & Clima e Temperatura & $74_{\mathrm{b}}$ \\
\hline $3^{\circ}$ ano E.M & Geografia & Condições Climáticas & $67 \mathrm{~b}$ \\
\hline $1^{\circ}$ ano E.M & História/Português & Revolução Industrial & $86_{\mathrm{a}}$ \\
\hline $2^{\circ}$ ano E.M & Sociologia/Filosofia & Revolução Industrial & $73_{\mathrm{a}}$ \\
\hline $1^{\circ}$ ano E.M & Educação Artística & Realismo/Naturalismo & $68_{\mathrm{f}}$ \\
\hline Total & 10 & 8 & 671 \\
\hline
\end{tabular}

$\mathrm{N}$ - Número de tópicos repetitivos encontrados no material didático desta pesquisa.

* Letras minúsculas igualitárias na vertical não diferem estatisticamente entre si.

E.M - Ensino Médio.

Fonte: Dados coletados pelo Autor (2017).

Provendo a análise do material existente de potencial interdisciplinar com tópicos da disciplina de Física, é notável o quanto pode ser possível a aplicabilidade interdisciplinar entre áreas diversificadas do conhecimento, porém essa linha de raciocínio deve partir da base do problema. É plausível perceber que a interdisciplinaridade, apesar de ainda pouco 
utilizada pelo corpo docente, não é mais um método completamente desconhecido, tendo um vasto material para a sua efetuação e aplicação em sala de aula. Apesar de encontrarmos materiais didáticos antigos, que necessitam de reformulação, é possível utilizar diversos tópicos dispostos na bibliografia, para a elaboração de conhecimentos provindos de bases interdisciplinares.

\section{CONSIDERAÇÕES FINAIS}

A pesquisa demonstra inúmeras possibilidades de construir um conhecimento livre da estagnação fragmentada, metodologia encontrada em nosso sistema educacional. Cada disciplina, por mais distante possível, ainda possui uma interligação convergente de ELOS com as demais disciplinas. Destaca-se que, a interdisciplinaridade possibilita modificações no ambiente educacional, tornando-o propício às reestruturações coletivas e críticas do conhecimento. A relevância dos princípios dimensionais pedagógicos e epistemológicos é imprescindível, elaborando modelos metodológicos positivistas em relação á interdisciplinaridade.

É necessário que haja remanejo metodológico no planejamento atual da rede de ensino, para que ocorra uma operacionalização curricular por meio de dimensões verticais e horizontais. A interdisciplinaridade é um movimento articulador, implicante à ideia de profundidade e complexidade crescente de conteúdos dispostos disciplinarmente. Deve ser considerado o início de uma jornada sócio educativa de nosso sistema, acreditando na criatividade e complementaridade intelectual.

A interdisciplinaridade é uma metodologia progressista; pode abranger áreas do conhecimento, envolvendo ações coletivas entre o corpo docente e discente, de modo a esclarecer a importância dos processos educacionais. Dessa forma, acredita-se que a interdisciplinaridade pode proporcionar uma aprendizagem de melhor qualidade, sendo coadjuvante na sistemática do processo de ensino.

\section{REFERÊNCIAS}

ALMEIDA, Maria; CARCALHO, Edgar. (orgs.). Educação e complexidade: os sete saberes e outros ensaios. São Paulo: Cortez, 2007.

AMARAL, Emília; FERREIRA, Mauro; LEITE, Ricardo; SEVERINO, Antônio. Novas Palavras (2 $\left.2^{a} e d\right)$. São Paulo: FDT, 2013. 
BASTOS, Remo. O surpreendente êxito do sistema educacional finlandês em um cenário global de educação mercantilizada. Revista Brasileira de Educação v. 22 n. 70 jul.-set. 2017. DOI 10.1590/s1413-24782017227040.

BITTENCOURT, Circe. Ensino de história: fundamentos e métodos ( $\left.2^{a} e d\right)$. São Paulo: Cortez, 2008.

BONJORNO, José. Física para o ensino médio. São Paulo: FTD, 2013.

BRASIL. Lei de Diretrizes e Bases. Lei no 9.394/96, de 20 de dezembro de 1996. Ministério da Educação e do Desporto. Parâmetros curriculares nacionais. Brasília: MEC/SEF, 1996. Disponível em: < http://portal.mec.gov.br/seesp/arquivos/pdf/lei9394_Idbn1.pdf>. Acesso em: 31 de março, 2018.

Ministério da Educação. Lei de Diretrizes e Bases da Educação Nacional: Medida Provisória N746. Diário Oficial da União, 2016. Acesso em: < http://portal.mec.gov.br/index.php?option=com_docman\&view=download\&alias=48601 mp-746-ensino-medio-link-pdf\&category_slug=setembro-2016-pdf\&ltemid=30192>.Acesso em: 13 dez. 2017.

Ministério da Educação. Parâmetros Curriculares Nacionais: Ensino Médio. Diário Oficial da União, 2002. Disponível em: <http://portal.mec.gov.br/seb/ arquivos/pdf/blegais.pdf>. Acesso em: 08 jan. 2016.

BROCKELMANN, Rita. Araribá Ciências $6^{\circ}$ ano ( $3^{\circ}$ ed). São Paulo: Moderna, 2010.

BRUNI, Aline. Projeto Ser Protagonista Química: $1^{\circ}$ ano do Ensino Médio (2ª̣ed). São Paulo: SMCAED-UFMG, 2013.

CARVALHO, Antônio; CARVALHO, Marlene; BARRETO, Motta; ALVES, Fábio. Andragogia: considerações sobre a aprendizagem do adulto. Ensino, Saúde e Ambiente, 2010. (20)1, 78-90. DOI:10.22409/esa.v3i1.108.

COIMBRA, Aveiro. Considerações sobre a interdisciplinaridade. In: Phillipi. J. R. A., Tucci, C. E. M; Hogan, D. J; Navegantes, R. (Org.) Interdisciplinaridade em ciências ambientais (52-70). São Paulo: Signus, 2000.

CORTELLA, Mario. Educação, Escola e Docência: novos tempos, novas atitudes. São Paulo: Cortez, 2014. 
COTRIM, Gilberto. Fundamentos da Filosofia: História e Grandes Temas (15aed). São Paulo: Saraiva, 2002.

Saber e Fazer História: ensino médio (2ªed). São Paulo: FTD, 2012.

CURY, Augusto. Superando o cárcere da emoção: a pior prisão do mundo. São Paulo: Acadêmica de inteligência, 2000.

DANTE, Roberto. Projeto Teláris Matemática: $7^{\circ}$ ano do Ensino Fundamental (2 $\left.{ }^{a} e d\right)$. São Paulo: Ática, 2015.

Ática, 2014.

Projeto Ápis Matemática: $4^{\circ}$ ano do Ensino Fundamental (2ªed). São Paulo:

DARBELLAY, Frédéric. Vers une théorie de l'interdisciplinarité? Entre unité et diversité. Nouvelles perspectives en sciences sociales, 2011. 7(1), 65-87.

DOI:10.7202/1007082ar

FAZENDA, Ivani. O que é interdisciplinaridade. São Paulo: Cortez, 2008.

Integração e Interdisciplinaridade no Ensino Brasileiro. São Paulo: Loyola, 2011.

. (Org.). Interdisciplinaridade: dicionário em construção. São Paulo: Cortez, 2001.

A Interdisciplinaridade: um projeto em parceria (5ªed). São Paulo: Loyola, 1993.

FERREIRA, Aurélio. Miniaurélio Século XXI: O minidicionário da língua portuguesa. Rio de Janeiro: Nova Fronteira, 2000.

FREIRE, Paulo. (1987). Pedagogia do oprimido. Rio de Janeiro: Paz e Terra, 1987.

FRIGOTTO, Gaudêncio. A interdisciplinaridade como necessidade e como problema nas ciências sociais. In: Jantsch, A. P., Bianchetti, L. (Orgs.). Interdisciplinaridade: para além da filosofia do sujeito (59-63). Petrópolis: Vozes, 1995. 
GADOTTI, Moacir. A organização do trabalho na escola: alguns pressupostos. São Paulo: Ática, 1993.

GOMES, Moacir. História do Ensino da Matemática: uma introdução. Belo Horizonte: CAED-UFMG, 2012.

GOULART, Renata; OLIVEIRA, Adir; ELY, Claudiane; FRUET, Lucas; FERREIRA, Paulo; MOOJEN, Renata. Os desafios da prática pedagógica interdisciplinar para a formação do professor de Educação Física. DO CORPO: Ciências e Artes, Caxias do Sul, v. 1, n. 2, jul./dez. 2011. Disponível em:

<http://www.ucs.br/etc/revistas/index.php/docorpo/article/view/2304/1367http://www.ucs.br /etc/revistas/index.php/docorpo/article/view/2304/1367>.Acesso em: 04 out, 2017.

GOWDAK, Demétrio; MARTINS, Eduardo. Ciências Novo Pensar $6^{\circ}$ ano $\left(2^{\circ} \mathrm{ed}\right)$. São Paulo: FDT, 2012.

GUIMARÃES, Valter. Formação de professores: saberes, identidade e profissão. São Paulo: Papirus, 2004.

JAPIASSU, Hilton. Interdisciplinaridade e patologia do saber. Rio de Janeiro: Imago, 1976.

LIMA, Lages. Matemática Elementar para o Ensino Médio (10ªed). Rio de Janeiro: SBM, 2012.

LOPES, Sônia; ROSSO, Sergio. Biologia Ensino Médio. São Paulo: Saraiva, 2010.

LUCK, Heloisa. Pedagogia Interdisciplinar: Fundamentos Teórico-metodológicos. Petrópolis: Vozes, 2001.

LUCKESI, Carlos. Filosofia da educação. São Paulo: Cortez, 1999.

MACHADO, Nilson. Educação: projetos e valores (3ª̣ed). São Paulo: Escrituras,2000.

MAGNÓLI, Demétrio. Geografia para o Ensino Médio. São Paulo: Saraiva, 2010.

MAGALHÃES, Cláudia; SOURIENT, Lilian; GONÇALVES, Marcos; RUDEK, Roseni. Projeto Apoema Geografia $6^{\circ}$ ano. ( $\left.2^{\circ} \mathrm{ed}\right)$. São Paulo: Editora do Brasil, 2015. 
MELANI, Raquel. Projeto Ser Protagonista História: $8^{\circ}$ ano do Ensino Fundamental (4ª ed). São Paulo: Moderna, 2012.

MENDELSON, Elliot. Introdução ao Cálculo (2ª̂ed). São Paulo: LTC, 2007.

MORAES, Cândida. O Paradigma Educacional Emergente (16ํㅜed). Campinas: Papirus, 2012.

NOVAIS, Vera. Química Geral e Inorgânica. São Paulo: Atual, 1993.

POMBO, Olga. Interdisciplinaridade: conceito, problema e perspectiva, 1993. Disponível em: <http://webpages.fc.ul.pt/ ommartins/mathesis/interdisciplinaridade.pdf >. Acesso em: 04 out, 2017.

SAMPAIO, José; CALÇADA, Caio. Universo da Física $\left(2^{\circ}\right.$ ed). São Paulo: Atual, 2015.

SANTIAGO, Fernando. Ser Protagonista Biologia: $1^{\circ}$ ano do Ensino Médio (3ªed). São Paulo: SM, 2013.

SANTOMÉ, Torres. Globalização e interdisciplinaridade: o currículo integrado. Porto Alegre: Artmed, 1998.

SAVIANI, Dermeval. Escola e Democracia (4ㄹed). São Paulo: Cortez, 1986.

SILVA, Robson; LIMA, Beatriz. Causa do aquecimento global: antropogênica versus natural. Terra e Didática, 2009. 5(1):42-49. Disponível em: <http://www.ige.unicamp.br/terraedidatica/>. Acesso em: 31 de março, 2018.

SPEYER, Edward. Seis Caminhos a partir de Newton: as grandes descobertas na física. Rio de Janeiro: Campus, 1995.

TOMAZZI, Nelson. Sociologia para o Ensino Médio. $3^{\circ}$ edição. São Paulo: Saraiva, 2013.

VEDOVATE, Carlo. Projeto Araribá Geografia: $2^{\circ}$ ano do Ensino Médio ( $\left.3^{\mathrm{a}} e d\right)$. São Paulo: Moderna, 2010. 